\title{
The Efficiency in Liquidity Measures during the US Monetary Announcements
}

\author{
Dimitrios I. Vortelinos ${ }^{1 *}$, Konstantinos Gkillas ${ }^{2}$, Christoforos Konstantatos ${ }^{2}$, \\ George Peppas ${ }^{3}$
}

${ }^{1}$ Lincoln International Business School, University of Lincoln, Lincoln, England

${ }^{2}$ Department of Business Administration, University of Patras, Patras, Greece

${ }^{3}$ Accounting Lab, Hellenic Open University, Patras, Greece

Email:^dvortelinos@lincoln.ac.uk,gillask@upatras.gr, ckonstanta@upa tras.gr,gpeppas@eap.gr

How to cite this paper: Vortelinos, D.I., Gkillas, K., Konstantatos, C. and Peppas, G. (2018) The Efficiency in Liquidity Measures during the US Monetary Announcements. Theoretical Economics Letters, 8, 98-110.

https://doi.org/10.4236/tel.2018.81006

Received: December 23, 2017

Accepted: January 26, 2018

Published: January 29, 2018

Copyright $\odot 2018$ by authors and Scientific Research Publishing Inc. This work is licensed under the Creative Commons Attribution International License (CC BY 4.0).

http://creativecommons.org/licenses/by/4.0/

\begin{abstract}
We examine the impact of US economic news releases in the liquidity of eleven not so extensively researched emerging stock markets. We employ ten liquidity measures. The sample begins from June 2007 up to December 2016. Analysis is performed in a weekly frequency. China is the least liquid Asian market. Peru is the most liquid Latin American market. Most of the emerging markets are positively affected by the US news, offering diversification benefits to international investors. India and Argentina (China and Chile) are the Asian and Latin American countries with the highest (lowest) impacts, respectively. There is not a single best-in-class liquidity measure. The country with the lowest liquidity has the lowest impact from the US news releases. This result holds for both groups of countries in Asia and Latin America.
\end{abstract}

\section{Keywords}

Bootstrap, Emerging Markets, Liquidity, US Economic News

\section{Introduction}

Most of the emerging markets yield spectacular returns; however, they are subject to tremendous risk and volatility. Illiquidity is always an important factor that drives institutional investors away from the emerging stock markets. Liquidity is not easy to be estimated, because of its ad-hoc definition and its determinants (Chen, Luo and Liu, [1]). The importance of liquidity is recently evidenced by Donadelli and Prosperi [2] and Switzer and Picard [3], among others. The effects of liquidity have been studied extensively by Christie-David and Chaudhry [4] by selecting five instruments that differ in liquidity and 
investigating how they react on macroeconomic release announcements. Evidence suggests that effects absorb fifteen minutes after the announcements and persist more in instruments with more liquidity. Fleming and Remolona [5] extended on how the prices and liquidity affected macroeconomic news releases.

Due to the strengths and weaknesses of each liquidity measure and proxy, we employ the ten most influential liquidity estimators to determine the efficiency and efficacy of each measure in representing emerging market liquidity. These are: turnover volume, two naive liquidity ratios, a conventional liquidity ratio, the Martin [6] liquidity index, Hui and Heubel [7] liquidity ratio, the Hasbrouck and Schwartz [8] market efficiency coefficient, the Hui and Heubel [7] Market-Adjusted liquidity, the Amihud [9] illiquidity index, the Liu [10] measure and the modified Amihud measure (Kang and Zhang, [11]).

There is overall informational efficiency, where the role of country-level institutional environments in the relation between information and stock prices is important (Dang, Moshirian and Zhang, [12]). Nikkinen et al. [13] was among the first and relatively recent papers to investigate such international efficiency in emerging stock markets through the effects of U.S. economic news releases on the market risk (volatility). The effect of U.S. economic news releases on the liquidity of Asian and Latin American emerging stock markets is answered in the present paper with an updated and different dataset as well.

This paper examines the efficiency of the ten most important liquidity measures in estimating liquidity of Asian and Latin American emerging stock markets, and then the time-series behavior for each liquidity measure of the eleven emerging stock markets. Finally, the impact of the most important US economic news releases affecting the liquidity of emerging stock markets is examined. The rest of the paper is organized as follows. Section 2 describes the data. Section 3 deploys the methodology. Section 4 describes the empirical results. Section 5 provides concluding remarks.

\section{Data}

Both Asian and Latin American markets have an increasing interest in literature, nowadays. Kim, Kim and Lee [14] found strong spillover effects in the Asian emerging markets occasionally causing US dollar liquidity problems. Kearney [15] and Agudelo, Giraldo and Villarraga [16] investigated the liquidity of these markets in detail. The present paper concentrates on Asian and Latin American emerging stock markets. Not all stock markets are developing; they all are increasingly important for their regions, however. They have been selected across most of the respective literature. These are the reasons why they were selected. The Latin American stock markets are: 1) Argentina, Buenos Aires Stock Exchange (MERcado de VALores) market index (MERVAL); 2) Brazil, Brazil stock exchange Bovespa Index (IBOVESPA); 3) Chile, Santiago Stock Exchange Index (IPSA); 4) Colombia, Colombian Securities Exchange (Bolsa de Valores de Colombia) index (IGBC); 5) Mexico, Mexican Stock Exchange (Bolsa 
Ipc) Index (MEXBOL); and 6) Peru, Peru Stock Market (IGBVL). The Asian stock markets are: 1) China, Shanghai Stock Exchange Composite Index (SHCOMP); 2) India, National Stock Exchange of India CNX Nifty index (NIFTY); 3) Indonesia, Jakarta Stock Exchange Composite Index (JCI); 4) South Korea, Korea Stock Exchange Kospi Index (KOSPI); and 5) Taiwan (China), Taiwan Stock Exchange Weighted Index (TWSE).

Daily prices of all stock indices are employed and are also expressed in US dollar. Liquidity is measured in a weekly frequency, however. The impact of the US economic news is also accessed in a weekly frequency. Using no daily data to examine the impact of economic news releases are among others, Hardouvelis [17], Boyd et al. [18], Lamont et al. [19], Vortelinos and Gkillas (Gillas) [20] and Vortelinos and Gkillas [21]. Data starts from 01/06/2007 to 31/12/2016. The financial crisis which begins with the Lehman Brother collapse was one of the most tumultuous economic events in the recent economic history. Is well known the contagion between US and emerging markets. Our data sample highlights the impact of recent financial crisis to emergency markets. More specific the sample concludes firstly, the sub-prime crisis phase 01/06/2007 to 14/09/2008 (the day before Lehman Brothers collapse). Secondly, the period between $15 / 09 / 2008$ to $01 / 05 / 2010$ the global financial crisis and thirdly, the period from $02 / 05 / 2010$ to end where the global financial crisis turns into sovereign debt crisis. Some of the recent studies on the impact of US macroeconomic announcements are Rosa [22] and Elder et al. [23], among others. Announcements data come from the Bureau of Economic Analysis and the US Census Bureau of the US Department of Commerce, the Bureau of Labor Statistics of the US Department of Labor, and the Board of governors of the Federal Reserve System.

Kuttner [24] introduced and Rosa [22] recently applied the monetary policy surprise. This measure can also be used as an unanticipated surprise measure for any macroeconomic surprise.

$$
S_{j, t}=\Delta f_{j, t} \cdot \frac{D}{D-d}
$$

where $\Delta f_{j, t_{i}}$ is the change in weekly actual (realized) macroeconomic variable $j$ (from week to week), $d$ is the day of the week of the meeting, and $D$ is the total number of days in that week. The variable Index is the observed tone of statement for any macroeconomic variable. Index $t_{t}=-1$ for bad news (in most of the cases, when negative change of macroeconomic variable's value); Index $_{t}=0$ for neutral news (in most of the cases, when no change of macroeconomic variable's value); and Index $x_{t}+1$ for good news (in most of the cases, when positive change of macroeconomic variable's value). The surprise component of any macroeconomic statement, the news shock $\left(N S_{j, t}\right)$, as the difference between what it is announced and what the market expects to announce:

$$
N S_{j, t}=\text { Index }_{t}-\text { Index }_{t-1}
$$


The US announcements concern the FED target rate as decided and communicated by the Board of governors of the Federal Reserve System. Usually, these announcements take place more than once a month regularly. The total number of the FED Funds Target Rate announcements employed by the present study, is twenty. This study employs only the most influential announcements within this period. The announcement time is at 10:00 am local time. We have not selected all FED rate announcements due to only few of the weekly FED announcements were not expected in the international financial markets.

\section{Methodology}

\subsection{Liquidity Measurement}

This paper employs ten liquidity measures. All liquidity measures are estimated in a weekly frequency. Due to the small number of the observation in a weekly frequency we apply a non-parametric bootstrap approach in each liquidity measure, re-sampling from the original dataset (see Efron and Tibshirani, [25]).

The first liquidity measure is the turnover volume $L_{t}^{T V}$ in $t$ weeks; second measure is the turnover rate $\left(L_{t}^{T R}\right)$ :

$$
L_{t}^{T R}=\frac{L_{t}^{T V}}{M C_{t}}=\frac{L_{t}^{T V}}{P_{t} \cdot S_{t}}
$$

where $L_{t}^{T R}$ is the turnover rate liquidity measure; $L_{t}^{T V}$ is the turnover volume; $M C_{t}$ is the market capitalization which equals to close price times number of shares outstanding $\left(P_{t} \cdot S_{t}\right)$; and, third measure the liquidity ratio $\left(L_{t}^{L R}\right)$ :

$$
L_{t}^{L R}=\frac{\Delta P_{t}}{L_{t}^{T V}}
$$

where $\Delta P_{t}$ is the close price changes; and $L_{t}^{T V}$ is the turnover volume. Another liquidity measure employed here, is the conventional liquidity ratio $\left(L_{t}^{C L R}\right.$ ) as examined in Gabrielsen, Marzo and Zagaglia [26]. This measure provides a measure for how much traded volume is necessary to induce a price change of one percent. Volumes and prices are the key ingredients. The analytical expression of the liquidity ratio index is:

$$
L_{t}^{C L R}=\frac{\sum_{i=1}^{5}\left(S_{i, t} \cdot P_{i, t}\right)}{\sum_{i=1}^{5}\left|\Delta P_{i, t}\right|}
$$

where $S_{i, t}$ and $P_{i, t}$ are the number of trades and closing price of day $i$ in week $t$. The liquidity ratio is usually computed for a number of assets and is aggregated over a pool with similar characteristics. The time interval $(T, t)$ adopted to compute the index is typically chosen arbitrarily; in this paper, $T$ equals to 5 (days) and $t$ measures weeks. This means that large volumes of trades have little influence on price, for high values of conventional liquidity ratio $\left(L_{t}^{C L R}\right)$. Obviously, this conceptual framework focuses more on the price aspect than on the issue of time or on the execution costs typically present in a market. 
Another liquidity measure is the Hui and Heubel [7] liquidity ratio ( $L_{t}^{H H}$ ) which relates the volumes of trade to their impact on prices, and thus also to resiliency. The lower the $L_{t}^{H H}$, the higher the liquidity.

$$
L_{t}^{H H}=\frac{\left[\left(h_{5, t}-l_{5, t}\right) / l_{5, t}\right]}{\left[V_{5, t} /\left(S_{5, t} \cdot \bar{P}_{5, t}\right)\right]}
$$

where $h_{5, t}$ and $l_{5, t}$ are the highest and lowest logarithmic daily prices over last 5 trading days; $t$ indicates the number of days (5-trading-days periods); $V_{20, t}$ is the total turnover volume traded last 5 days; $S_{5, t}$ is the number of trades within a 5-days period; and $\bar{P}_{5, t}$ is the average closing price over a 5-day period. Unrefined measures of liquidity could be nothing more than some kind of weighted average reflecting the frequency with which new information hits an index as compared with another. Hasbrouck and Schwartz [8] proposed the market efficiency coefficient $\left(L_{t}^{M E C}\right)$ to distinguish short-term from long-term price changes. The $L_{t}^{M E C}$ exploits the fact that price movements are more continuous in liquid markets, even if information is affecting equilibrium prices. Thus, for a given permanent price change, the transitory changes to that price should be minimal in resilient markets. The long-period variance is approximated by the weekly realized range; and the short-period variance is approximated by the average daily range over a week.

$$
L_{t}^{M E C}=\frac{V_{t}^{W R R}}{\left(T \cdot V_{t}^{D R}\right)}
$$

where $t$ is the number of week; $T$ is the number of short periods in each longer period (i.e. 5 trading days per week); $V_{t}^{D R}$ is the average short-period (daily) volatility (range), as initially introduced by Parkinson [27]:

$$
V_{t}^{D R}=\frac{1}{5} \cdot \sum_{i=1}^{5} \frac{h_{i}-l_{i}}{4 \log (2)}
$$

where $h_{i}$ and $l_{i}$ are the high and low logarithmic prices for each $i$ trading day within $t$ week; and, $V_{t}^{W R R}$ is the long-period (weekly) volatility (realized range), as proposed by Martens, and van Dijk [28]:

$$
V_{t}^{W R R}=\frac{1}{4 \log (2)} \sum_{i=1}^{5}\left(h_{i, t}-l_{i, t}\right)^{2}
$$

where $h_{i, t}$ and $l_{i, t}$ are the within the $i$-th daily high and low logarithmic prices for each $t$ week ( 5 trading days period); and $L_{t}^{M E C}$ tends to be closer but slightly below one in more resilient markets. Hui and Heubel [7] suggested the Market-Adjusted liquidity ( $L_{t}^{M A}$ ) for equities. This liquidity measure (as any liquidity measure in this paper) is estimated in a weekly frequency. Firstly, the beta $(\beta)$ coefficient is estimated in a weekly frequency via the capital asset pricing model (CAPM); where, the five daily returns of an aggregate emerging stock market index ${ }^{1}$ are regressed on the twenty corresponding daily returns of ${ }^{1}$ The aggregated emerging stock market index is a weighted average of all eleven emerging stock indices, examined in the present paper. Weights are selected depending on the contribution of each index's volume turnover to the summation. 
each emerging stock index. So, there is one point estimate of $\beta$ coefficient per week.

$$
R_{i, t}=\alpha_{t}+\beta_{t} \cdot R_{m, t}+u_{i, t}
$$

where $R_{i, t}$ is the daily return on day $i$ and week $t, R_{m, t}$ is the daily market (aggregated) return; $\beta$ is the weekly regression coefficient (systematic risk); $u_{i, t}$ is the regression residuals (or specific risk).

$$
u_{i, t}^{2}=\gamma+L_{t}^{M A} \cdot V_{i, t}+e_{i, t}
$$

where $u_{i, t}^{2}$ is the squared residuals from the former (CAPM) equation; $L_{t}^{M A}$ is the weekly point estimate of market-adjusted liquidity; $V_{i, t}$ is the daily turnover volume traded for each of the twelve emerging stock indices; and, $e_{i, t}$ is the residuals of the latter equation. The market-adjusted liquidity uses the residual of a regression of the index's return on the return of the aggregated emerging market (thus purging it from its systematic risk) to determine the intrinsic liquidity of any index. The smaller $L_{t}^{M A}$, the smaller the impact of trading volume on the variability of the indices' price and therefore, the index is more liquid. Another employed liquidity index is an index of illiquidity ( $L_{t}^{\text {illiq }}$ ) introduced by Amihud [9].

$$
L_{t}^{i l l i q}=\frac{1}{20} \sum_{i=1}^{20} \frac{\left|R_{i, t}\right|}{V_{i, t}}
$$

where $R_{i, t}$ and $V_{i, t}$ are the daily-price return and the daily turnover volume accordingly, in day $i$ and week $t$. This illiquidity index provides only a rough measure of the price impact on liquidity. A recent paper that examined the $L_{t}^{\text {illi }}$ illiquidity index is Gabrielsen, Marzo and Zagaglia [26] and Karolyi, Lee and Van Dijk [29]. Liu [10] introduced the standardized turnover-adjusted number of zero daily volumes over the prior x weeks ( $L_{t}^{L i u}$ ). Results are reported only for the 1-week prior Liu's measure as reported in Kang and Zhang [11]:

$$
L_{t}^{L i u}=\left[N^{\text {prior }}+\frac{1 /\left(1-L_{t}^{T V}\right)}{D e f l}\right] \times \frac{5}{N_{t-1}}
$$

where $L_{t}^{T V}$ is the $t$-week turnover; Defl is the same across all emerging markets and set to be $0<\frac{1 /\left(1-L_{t}^{T V}\right)}{D e f l}<1 ; N^{\text {prior }}$ is the number of zero daily volumes in prior $\times$ week ( 1 week, here); $N_{t-1}$ is the total number of trading days in prior $\times$ weeks (1 week, here). Kang and Zhang [11] introduced the modified Amihud measure ( $L_{t}^{\text {Adj-illiq }}$ ):

$$
L_{t}^{\text {Adj-illiq }}=\left[\ln \left(\frac{1}{N} \sum_{i=1}^{N} \frac{\left|R_{i, t}\right|}{V_{i, t}}\right)\right] \times\left(1+Z V_{t}\right)
$$

where $N$ is the number of non-zero trading volume days within week $t ;\left|R_{i, t}\right|$ is the absolute value of the return on day $i$ and week $t, V_{i, t}$ is the US dollar trading volume on day $i$ and week $t$, and, $Z V_{t}$ is the percentage of zero-volume days within week $t$. 


\subsection{Impact of News Releases}

This sub-section reveals the methodology of the response of US economic news releases on liquidity of twelve emerging stock markets. Regressions, similar to those used in Chulia, Martens and van Dijk, [30] and Gospodinov and Jamali [31], are employed. Regressing dummy variables on the first differences of liquidity is employed here to examine the effect of news on liquidity:

$$
\Delta L_{t}=\alpha+\beta_{j} \cdot D_{j, t}+\epsilon_{t}
$$

where $D_{j, t}$ is the dummy variable for the $j$ category of news, $\Delta L_{t}=L_{t}-L_{t-1}$ is the change in the level of liquidity between the week of the news releases and the previous week. It is common in literature to use first differences in such method ${ }^{2}$. Moreover, Newey and West's [33] heteroskedasticity and autocorrelation consistent (HAC) standard errors are used to ensure valid inference.

\section{Empirical Results}

\subsection{Time Series Behavior of Liquidity}

Table 1(a) and Table 1(b) provide the descriptive statistics of the twelve emerging stock markets across the ten liquidity measures; results are split into regions. The mean and mean-to-standard deviation statistics are compared regionally and internationally. According to Table 1(a), India and Peru are the Asian and Latin American countries with the highest liquidity respectively, across all liquidity measures. China and Chile are the least liquid Asian and Latin American markets, respectively. Taiwan (China) and Peru are the Asian and Latin American areas with the highest average to standard deviation liquidity ratios respectively, across all liquidity measures (Table 1(b)). China and Colombia are the Asian and Latin American countries with the lowest average to standard deviation liquidity ratios respectively, across all measures.

\subsection{Impact of News Releases}

This section researches the impact and significance of announcements and events on the corresponding emerging stock markets. The impact of announcements is assessed via ordinary least squares (OLS) regressions. The error term of the asymmetric regressions is assumed to be iid across all equations for asymmetries (see Amira, Taamouti and Tsafack [34]). Standard errors (S.E.) in all equations are based on the Newey-West estimator of the variance-covariance matrix (see, Dufour, Pelletier and Renault [35]).

The results of the impact of US announcements on liquidity series are reported in Table 2 and Table 3 for the Asian and Latin American countries, respectively. Empirical findings are presented across all liquidity measures. Starting with the Asian countries (Table 2), most of the news-releases coefficients (impacts) on Asian countries are statistically significant and positive. This is strong evidence that Asian countries are affected by the US economic 
Table 1. (a) Descriptive statistics (average); (b) Descriptive statistics (average to standard deviation).

(a)

\begin{tabular}{|c|c|c|c|c|c|c|c|c|c|c|}
\hline & $L_{t}^{T V}$ & $L_{t}^{T R}$ & $L_{t}^{L R}$ & $L_{t}^{C L R}$ & $L_{t}^{H H}$ & $L_{t}^{M E C}$ & $L_{t}^{M A}$ & $L_{t}^{i l l i q}$ & $L_{t}^{L i u}$ & $L_{t}^{\text {Adj-illiq }}$ \\
\hline & \multicolumn{10}{|c|}{ Panel A. Asia } \\
\hline China & 0.5038 & 0.5969 & 0.0002 & 0.0752 & 0.0001 & 0.1101 & 0.0004 & 0.0005 & 0.3035 & 0.0005 \\
\hline India & 0.0094 & 0.0058 & 0.0153 & 0.0826 & 0.0143 & 0.0921 & 0.0034 & 0.0244 & 0.0961 & 0.0244 \\
\hline Indonesia & 0.2033 & 0.2166 & 0.0005 & 0.0882 & 0.0004 & 0.0906 & 0.0024 & 0.0010 & 0.0654 & 0.0010 \\
\hline South Korea & 0.0216 & 0.0385 & 0.0024 & 0.0947 & 0.0019 & 0.0807 & 0.0006 & 0.0085 & 0.0681 & 0.0085 \\
\hline \multirow[t]{2}{*}{$\begin{array}{l}\text { Taiwan } \\
\text { (China) }\end{array}$} & 0.1592 & 0.0664 & 0.0013 & 0.0987 & 0.0011 & 0.0783 & 0.0008 & 0.0011 & 0.0706 & 0.0011 \\
\hline & \multicolumn{10}{|c|}{ Panel B. Latin America } \\
\hline Argentina & 0.0005 & 0.0007 & 0.2163 & 0.0668 & 0.1354 & 0.1312 & 0.4378 & 0.5455 & 0.0650 & 0.5455 \\
\hline Brazil & 0.0432 & 0.0038 & 0.1428 & 0.0687 & 0.0910 & 0.1074 & 0.0023 & 0.0159 & 0.0653 & 0.0159 \\
\hline Chile & 0.0294 & 0.0260 & 0.0032 & 0.1173 & 0.0033 & 0.0650 & 0.0016 & 0.0052 & 0.0670 & 0.0052 \\
\hline Colombia & 0.0182 & 0.0442 & 0.0075 & 0.1192 & 0.0061 & 0.0709 & 0.0041 & 0.0255 & 0.0650 & 0.0255 \\
\hline Mexico & 0.0107 & 0.0010 & 0.0677 & 0.1014 & 0.0767 & 0.0762 & 0.0039 & 0.0167 & 0.0650 & 0.0167 \\
\hline Peru & 0.0007 & 0.0001 & 0.5429 & 0.0873 & 0.6696 & 0.0975 & 0.5434 & 0.3558 & 0.0691 & 0.3558 \\
\hline
\end{tabular}

(b)

\begin{tabular}{|c|c|c|c|c|c|c|c|c|c|c|}
\hline & $L_{t}^{T V}$ & $L_{t}^{T R}$ & $L_{t}^{L R}$ & $L_{t}^{C L R}$ & $L_{t}^{H H}$ & $L_{t}^{M E C}$ & $L_{t}^{M A}$ & $L_{t}^{\text {illiq }}$ & $L_{t}^{L i t}$ & $L_{t}^{\text {Adj-illiq }}$ \\
\hline & \multicolumn{10}{|c|}{ Panel A. Asia } \\
\hline China & 6.5732 & 4.5434 & 0.7284 & 3.2205 & 1.1348 & 2.8919 & 1.6691 & 1.2665 & 1.6412 & 1.2669 \\
\hline India & 2.5112 & 2.3269 & 1.0101 & 4.1971 & 1.7534 & 3.1671 & 1.5666 & 1.4138 & 3.5771 & 1.4138 \\
\hline Indonesia & 3.4240 & 2.5157 & 0.8127 & 3.5994 & 1.5993 & 2.5790 & 1.7473 & 1.4764 & 1.6838 & 1.4764 \\
\hline South Korea & 2.5378 & 2.6254 & 0.8576 & 4.1797 & 1.6888 & 3.4513 & 1.0662 & 2.1233 & 3.5747 & 2.1232 \\
\hline \multirow[t]{2}{*}{$\begin{array}{l}\text { Taiwan } \\
\text { (China) }\end{array}$} & 3.4098 & 2.8733 & 0.8669 & 4.2513 & 1.9948 & 3.4513 & 0.8901 & 2.3261 & 3.5898 & 2.3255 \\
\hline & \multicolumn{10}{|c|}{ Panel B. Latin America } \\
\hline Argentina & 1.6358 & 1.1760 & 1.0745 & 2.4043 & 1.6118 & 3.6036 & 2.9156 & 3.2582 & 3.5699 & 3.2582 \\
\hline Brazil & 0.4505 & 0.3534 & 0.9122 & 4.7617 & 1.3681 & 4.1730 & 1.2685 & 1.2613 & 3.5625 & 1.2613 \\
\hline Chile & 2.6525 & 1.9851 & 0.6985 & 3.5899 & 1.6385 & 2.7055 & 2.2882 & 1.7931 & 3.5677 & 1.7931 \\
\hline Colombia & 1.1040 & 0.9611 & 0.3954 & 3.1309 & 0.7399 & 2.5098 & 0.5919 & 0.7119 & 3.5022 & 0.7119 \\
\hline Mexico & 2.6497 & 2.3722 & 1.0690 & 3.8075 & 2.2358 & 3.3418 & 2.0235 & 1.8146 & 3.5711 & 1.8146 \\
\hline Peru & 0.7975 & 0.8137 & 2.0955 & 2.9469 & 4.9891 & 1.9523 & 3.6040 & 2.3507 & 3.5712 & 2.3507 \\
\hline
\end{tabular}

Notes. (a) Provides the descriptive statistics (average) of the eleven emerging stock markets across the eleven liquidity measures; results are split into two regions: Asia and Latin America; (b) Provides the descriptive statistics (average to standard deviation) of the eleven emerging stock markets across the eleven liquidity measures; results are split into two regions: Asia and Latin America.

news releases. India and China are the Asian countries with the highest and lowest impacts, respectively. The least impact on China is also revealed by the 
Table 2. Impact of news releases, Asia.

\begin{tabular}{|c|c|c|c|c|c|c|c|c|c|c|c|}
\hline & & $L_{t}^{T V}$ & $L_{t}^{T R}$ & $L_{t}^{L R}$ & $L_{t}^{C L R}$ & $L_{t}^{H H}$ & $L_{t}^{M E C}$ & $L_{t}^{M A}$ & $L_{t}^{i l i q}$ & $L_{t}^{L i u}$ & $L_{t}^{\text {Adj-illiq }}$ \\
\hline \multirow[t]{3}{*}{ China } & $a$ & 0.0528 & 0.4959 & $-0.1272^{\star *}$ & $1.1652^{* *}$ & -0.0761 & -0.0132 & -0.0265 & -0.0002 & $3.1520^{*}$ & -0.0007 \\
\hline & $\beta$ & $-0.1172^{\star *}$ & $-1.0410^{*}$ & $0.4754^{* *}$ & $-1.3287^{\star}$ & 0.1617 & 0.0060 & $0.0508^{*}$ & 0.0002 & $-6.0420^{*}$ & 0.0010 \\
\hline & $\operatorname{adj} R^{2}$ & 0.0329 & 0.0229 & 0.0278 & 0.0219 & 0.0008 & 0.0001 & 0.0034 & 0.0080 & 0.0610 & 0.0082 \\
\hline \multirow[t]{3}{*}{ India } & $a$ & $0.0012^{\star *}$ & $0.0089^{\star *}$ & -5.1904 & 0.0367 & -5.1414 & $0.0695^{\star *}$ & -0.0791 & $-0.0150^{* *}$ & 0.0122 & $-0.0651^{\star *}$ \\
\hline & $\beta$ & $-0.0021^{\star *}$ & $-0.0183^{\star *}$ & 4.3504 & 0.4904 & 12.4776 & $-0.1503^{\star *}$ & $0.1517^{*}$ & $0.0191^{* *}$ & $-0.0250^{* *}$ & $0.0827^{* *}$ \\
\hline & $\operatorname{adj} R^{2}$ & 0.0580 & 0.0792 & 0.0007 & 0.0018 & 0.0129 & 0.0688 & 0.0037 & 0.0305 & 0.0796 & 0.0305 \\
\hline \multirow[t]{3}{*}{ Indonesia } & $a$ & $0.0368^{\star}$ & 0.3132 & -0.0922 & $1.8165^{\star *}$ & 0.7434 & -0.0451 & $-0.1035^{\star \star}$ & $-0.0010^{* *}$ & 10.5100 & $-0.0045^{\star *}$ \\
\hline & $\beta$ & $-0.0742^{\star \star}$ & $-0.7596^{\star \star}$ & 0.1547 & $-2.8455^{\star \star}$ & 0.0588 & 0.0675 & $0.1982^{\star *}$ & $0.0019^{\star *}$ & -20.4600 & $0.0083^{\star *}$ \\
\hline & $\operatorname{adj} R^{2}$ & 0.0478 & 0.0295 & 0.0010 & 0.0411 & 0.0001 & 0.0128 & 0.0131 & 0.0615 & 0.0410 & 0.0614 \\
\hline \multirow[t]{3}{*}{ Korea } & $a$ & $0.0026^{\star *}$ & $0.0481^{\star \star}$ & $-1.2144^{\star}$ & 0.1822 & 4.4820 & 0.0399 & -0.0028 & -0.0011 & 0.0764 & -0.0048 \\
\hline & $\beta$ & $-0.0054^{\star *}$ & $-0.1049^{\star *}$ & $3.1600^{\star *}$ & 0.1895 & -6.4050 & $-0.0800^{*}$ & $0.0054^{*}$ & 0.0020 & $-0.1642^{\star *}$ & 0.0087 \\
\hline & $\operatorname{adj} R^{2}$ & 0.0807 & 0.0744 & 0.0120 & 0.0002 & 0.0479 & 0.0279 & 0.0042 & 0.0023 & 0.0767 & 0.0023 \\
\hline \multirow[t]{3}{*}{ Taiwan (China) } & $a$ & $0.0396^{\star \star}$ & $0.1210^{\star *}$ & 0.1534 & 0.8271 & -2.6034 & -0.0304 & $-0.0006^{* *}$ & -0.0004 & $0.2026^{*}$ & -0.0018 \\
\hline & $\beta$ & $-0.0811^{\star \star}$ & $-0.2577^{\star *}$ & -0.1265 & -0.5217 & $7.8540^{\star *}$ & 0.0457 & $0.0001^{\star \star}$ & $0.0007^{\star *}$ & $-0.4274^{\star *}$ & $0.0033^{\star *}$ \\
\hline & $\operatorname{adj} R^{2}$ & 0.2019 & 0.1531 & 0.0001 & 0.0014 & 0.0432 & 0.0161 & 0.0054 & 0.0183 & 0.1405 & 0.0185 \\
\hline
\end{tabular}

Notes. Table 2 reports the costant (a) and slope ( $\beta$ ) coefficients as well as the adj $R^{2}$, regarding the impact of US economic news releases on Asian emerging stock markets. ${ }^{*}$ and ${ }^{* *}$ indicate significance in the $10 \%$ and $5 \%$ significance level, respectively.

Table 3. Impact of news releases, Latin America.

\begin{tabular}{|c|c|c|c|c|c|c|c|c|c|c|c|}
\hline & & $L_{t}^{T V}$ & $L_{t}^{T R}$ & $L_{t}^{L R}$ & $L_{t}^{C L R}$ & $L_{t}^{H H}$ & $L_{t}^{M E C}$ & $L_{t}^{M A}$ & $L_{t}^{\text {illiq }}$ & $L_{t}^{L i u}$ & $L_{t}^{\text {Adj-illiq }}$ \\
\hline \multirow[t]{3}{*}{ Argentina } & $a$ & 0.0003 & -0.0006 & -0.0534 & $1.5972^{\star *}$ & -0.0367 & 0.0159 & -1.5390 & $-0.3279^{\star *}$ & -0.0857 & $-0.1428^{\star *}$ \\
\hline & $\beta$ & 0.0005 & 0.0009 & $0.2327^{\star}$ & $-3.4089^{* *}$ & 0.1517 & 0.0088 & $2.9460^{*}$ & $0.6957^{\star *}$ & 0.1199 & $0.3023^{* *}$ \\
\hline & $\operatorname{adj} R^{2}$ & 0.0033 & 0.0032 & 0.0417 & 0.1317 & 0.0074 & 0.0002 & 0.0192 & 0.0850 & 0.0032 & 0.0850 \\
\hline \multirow[t]{3}{*}{ Brazil } & $a$ & $-0.0486^{\star \star}$ & $-0.0323^{\star \star}$ & $0.1532^{\star *}$ & -0.4365 & -0.0465 & $0.0815^{\star *}$ & $-0.0011^{\star}$ & 0.0027 & $-4.6620^{* *}$ & 0.0001 \\
\hline & $\beta$ & 0.0297 & 0.0148 & $-0.2844^{\star *}$ & 0.9882 & $0.1558^{* *}$ & $-0.1738^{* *}$ & $0.0204^{\star *}$ & 0.0027 & $2.1780^{\star *}$ & 0.0012 \\
\hline & $\operatorname{adj} R^{2}$ & 0.0158 & 0.0118 & 0.1356 & 0.0116 & 0.0182 & 0.1028 & 0.0298 & 0.0016 & 0.0125 & 0.0016 \\
\hline \multirow[t]{3}{*}{ Chile } & $a$ & -0.0024 & -0.0262 & $-0.0033^{* *}$ & 1.3599 & $-0.0059^{* *}$ & -0.0035 & -0.0073 & -0.0032 & $-3.9480^{* *}$ & -0.0014 \\
\hline & $\beta$ & 0.0027 & 0.0276 & $0.0066^{\star *}$ & -1.9404 & $0.0141^{\star *}$ & -0.0170 & $0.0139^{* *}$ & $0.0062^{\star *}$ & $4.3620^{* *}$ & $0.0027^{\star *}$ \\
\hline & $\operatorname{adj} R^{2}$ & 0.0034 & 0.0053 & 0.1086 & 0.0082 & 0.0629 & 0.0010 & 0.0245 & 0.0224 & 0.0064 & 0.0224 \\
\hline \multirow[t]{3}{*}{ Colombia } & $a$ & 0.0028 & -0.0051 & 0.0029 & 1.2672 & 0.0012 & -0.0326 & -0.0031 & -0.0052 & -9.0580 & -0.0023 \\
\hline & $\beta$ & -0.0054 & 0.0056 & $-0.0059^{*}$ & -1.3038 & $0.0124^{*}$ & 1.9620 & 0.0059 & 0.0020 & 16.7060 & 0.0009 \\
\hline & $\operatorname{adj} R^{2}$ & 0.0085 & 0.0001 & 0.0295 & 0.0039 & 0.0040 & 0.0057 & 0.0002 & 0.0001 & 0.0020 & 0.0003 \\
\hline \multirow[t]{3}{*}{ Mexico } & $a$ & $0.0021^{\star *}$ & $0.0017^{\star *}$ & 0.0294 & $-3.2418^{\star *}$ & $-0.3492^{\star *}$ & $0.0440^{*}$ & -0.0114 & -0.0029 & $0.2332^{\star *}$ & -0.0012 \\
\hline & $\beta$ & $-0.0039^{\star \star}$ & $-0.0035^{\star \star}$ & $-0.0599^{*}$ & $6.2802^{\star *}$ & $0.6763^{* *}$ & $-0.0864^{\star *}$ & 0.0218 & 0.0052 & $-0.4640^{* *}$ & 0.0023 \\
\hline & $\operatorname{adj} R^{2}$ & 0.2139 & 0.1267 & 0.0356 & 0.1317 & 0.3111 & 0.0445 & 0.0048 & 0.0057 & 0.1259 & 0.0057 \\
\hline \multirow[t]{3}{*}{ Peru } & $a$ & 0.0001 & 0.0006 & 0.1263 & $2.1435^{\star *}$ & $-0.9223^{\star}$ & -0.0368 & -1.0481 & $-0.2804^{*}$ & $0.0800^{\star *}$ & $-0.1219^{*}$ \\
\hline & $\beta$ & -0.0001 & $-0.0012^{\star}$ & -0.4050 & $-3.2634^{\star *}$ & $2.0196^{\star *}$ & 0.0680 & 2.0055 & $0.5255^{\star *}$ & $-0.1570^{\star *}$ & $0.2288^{\star *}$ \\
\hline & $\operatorname{adj} R^{2}$ & 0.0013 & 0.0238 & 0.0117 & 0.0511 & 0.0130 & 0.0078 & 0.0019 & 0.0295 & 0.0238 & 0.0297 \\
\hline
\end{tabular}

Notes. Table 3 reports the costant (a) and slope $(\beta)$ coefficients as well as the adj $R^{2}$, regarding the impact of US economic news releases on Latin American emerging stock markets. ${ }^{*}$ and ${ }^{* *}$ indicate significance in the $10 \%$ and $5 \%$ significance level, respectively. 
lowest adjusted $R^{2}$, across all Asian countries; whereas, the highest model significance is for Indonesia. According to Table 3, the liquidity of most of the Latin American countries are statistically significantly and positively affected by the US news releases. Argentina and Chile are the Latin American countries with the highest and lowest impacts, respectively. The Latin American countries with either the highest or lowest impact do not offer the highest (Mexico) or lowest (Colombia) model explanatory power, based on the adjusted $R^{2}$.

For both Asian and Latin American countries, the coefficient representing all other (than US news releases) factors explaining liquidity (alpha a coefficient) is statistically significant and high enough in absolute magnitude. Most of a coefficients are negative, meaning that other factors adversely affect liquidity. Regarding the Asian countries, turnover volume $\left(L_{t}^{T V}\right)$, turnover rate $\left(L_{t}^{T R}\right)$ and market adjusted liquidity $\left(L_{t}^{M A}\right)$ are the liquidity measures with the most statistically significant and highest in-absolute-terms impacts. For the Latin American countries, liquidity ratio $\left(L_{t}^{L R}\right)$, Hui and Heubel ([7] liquidity ratio $\left(L_{t}^{H H}\right)$ and Liu [10] measure are the measures with the most statistically significant and highest in-absolute-terms impacts. So, there is not a single measure better than the others.

\section{Concluding Remarks}

India and Peru (China and Chile) are the Asian and Latin American countries with the highest (lowest) liquidity respectively, across all liquidity measures. Taiwan (China) and Peru are the Asian and Latin American areas with the highest average to standard deviation liquidity ratios respectively. However, China and Colombia are the Asian and Latin American countries with the lowest average to standard deviation liquidity ratios respectively. Furthermore, there is strong evidence that Asian and Latin American countries are positively and significantly affected by the US economic news releases. India and China are the Asian countries with the highest and lowest impacts, respectively. Argentina and Chile are the Latin American countries with the highest and lowest impacts, respectively. It should be mentioned that the country with the lowest liquidity has the lowest impact from the US news releases. For Asia, this country is China; and for Latin America, this country is Chile. Moreover, there is not a single liquidity measure providing more significant impacts than the others, for both Asian and Latin American countries. So, a new liquidity measure specifically designed for emerging markets is needed to be introduced. It should also be considered that only the US news releases factor was employed to explain emerging markets liquidity. This is why the significant alpha (a) coefficient that incorporates all other explanatory factors of liquidity (except for US news) was statistically significant and negative in most of countries and liquidity measures.

\section{References}

[1] Chen, L., Luo, J. and Liu, H. (2013) The Determinants of Liquidity with G-RJMCMC-VS Model: Evidence from China. Economic Modelling, 35, 192-198. 
https://doi.org/10.1016/j.econmod.2013.06.020

[2] Donadelli, M. and Prosperi, L. (2012) On the Role of Liquidity in Emerging Markets Stock Prices. Resource Economics, 66, 320-348. https://doi.org/10.1016/j.rie.2012.06.001

[3] Switzer, L. and Picard, A. (2015) Idiosyncratic Volatility, Momentum, Liquidity, and Expected Stock Returns in Developed and Emerging Markets. Multinational Finance Journal, 19, 169-221.

[4] Christie-David, R. and Chaudhry, M. (1999) Liquidity and Maturity Effects around News Releases. Journal of Financial Research, 22, 47-67. https://doi.org/10.1111/j.1475-6803.1999.tb00714.x

[5] Fleming, M.J. and Remolona, E.M. (1999) Price Formation and Liquidity in the U.S. Treasury Market: The Response to Public Information. The Journal of Finance, 54, 1901-1915. https://doi.org/10.1111/0022-1082.00172

[6] Martin, P. (1975) Analysis If the Impact of Competitive Rates on the Liquidity of NYSE Stocks. Working Paper, Securities and Exchange Commission, No. 75-3.

[7] Hui, B. and Heubel, B. (1984) Comparative Liquidity Advantages among Major U.S. Stock Markets. Working Paper, DRI Financial Information Group Study Series, No. 84081.

[8] Hasbrouck, J. and Schwartz, R.A. (1988) Liquidity and Execution Costs in Equity Markets. The Journal of Portfolio Management, 14, 10-16.

https://doi.org/10.3905/jpm.1988.409160

[9] Amihud, Y. (2002) Illiquidity and Stock Returns: Cross Section and Time Series Effects. Journal of Financial Markets, 5, 31-56. https://doi.org/10.1016/S1386-4181(01)00024-6

[10] Liu, W. (2006) A Liquidity-Augmented Capital Asset Pricing Model. The Journal of Financial Economics, 82, 631-671. https://doi.org/10.1016/j.jfineco.2005.10.001

[11] Kang, W. and Zhang, H. (2014) Measuring Liquidity in Emerging Markets. Pacific-Basin Finance Journal, 27, 49-71.

[12] Dang, T.L., Moshirian, F. and Zhang, B. (2015) Commonality in News around the World. Journal of Financial Economics, 116, 82-110. https://doi.org/10.1016/j.jfineco.2014.11.007

[13] Nikkinen, J., Omran, M., Sahlstrom, P. and Aiijo, J. (2006) Global Stock Market Reactions to Scheduled U.S. Macroeconomic News Announcements. Global Finance Journal, 17, 92-104. https://doi.org/10.1016/j.gfj.2006.06.003

[14] Kim, B.-H., Kim, H. and Lee, B.-S. (2015) Spillover Effects of the U.S. Financial Crisis on Financial Markets in Emerging Asian Countries. International Review of Economics \& Finance, 39, 192-210. https://doi.org/10.1016/j.iref.2015.04.005

[15] Kearney, C. (2012) Emerging Markets Research: Trends, Issues, and Future Direction. Emerging Markets Review, 13, 159-183. https://doi.org/10.1016/j.ememar.2012.01.003

[16] Agudelo, D., Giraldo, S. and Villarraga, E. (2015) Does PIN Measure Information? Informed Trading Effects on Returns and Liquidity in Six Emerging Markets. International Review of Economics \& Finance, 39, 149-161.

[17] Hardouvelis, G.A. (1988) Economic News, Exchange Rates and Interest Rates. Journal of International Money and Finance, 7, 23-35. https://doi.org/10.1016/0261-5606(88)90003-4

[18] Îoyd, J.H., Hu, J. and Jagannathan, R. (2005) The Stock Market's Reaction to Un- 
employment News: Why Bad News Is Usually Good for Stocks. The Journal of Finance, 60, 649-672. https://doi.org/10.1111/j.1540-6261.2005.00742.x

[19] Lamont, O., Frazzini, A., Baker, M., Huberman, G., Wurgler, J. and Xiong, W. (2007) NBER Working Paper Series. The Earnings Announcement Premium and Trading Volume. https://doi.org/10.3386/w13090

[20] Parkinson, M. (1980) The Extreme Value Method for Estimating the Variance of the Rate of Return. The Journal of Business, 53, 6-15. https://doi.org/10.1086/296071

[21] Vortelinos, D. and Gkillas, K. (2017) Reaction of EU Stock Markets to ECB Policy Interventions. International Journal of Banking, Accounting and Finance, Forthcoming.

[22] Vortelinos, D. and Gkillas, K. (2016) The Effect of the European Economic News Releases to the US Financial Markets in the Crisis Period. Investment Management and Financial Innovations (Open-Access), 13. https://doi.org/10.21511/imfi.13(4).2016.04

[23] Rosa, C. (2011) Words That Shake Traders: The Stock Market's Reaction to Central Bank Communication in Real Time. Journal of Empirical Finance, 18, 915-934. https://doi.org/10.1016/j.jempfin.2011.07.005

[24] Elder, J., Miao, H. and Ramchander, S. (2012) Impact of Macroeconomic News on Metal Futures. Journal of Banking \& Finance, 36, 51-65.

https://doi.org/10.1016/j.jbankfin.2011.06.007

[25] Kuttner, K.N. (2001) Monetary Policy Surprises and Interest Rates: Evidence from the Fed Funds Futures Market. Journal of Monetary Economics, 47, 523-544. https://doi.org/10.1016/S0304-3932(01)00055-1

[26] Efron, B. and Tibshirani, R. (1993) An Introduction to the Bootstrap. Chapman and Hall, New York, London.

[27] Gabrielsen, A., Marzo, M. and Zagaglia, P. (2012) Measuring Market Liquidity: An Introductory Survey. Working Paper, RCEA, No. WP 12-02.

[28] Martens, M. and van Dijk, D. (2007) Measuring Volatility with the Realized Range. Journal of Econometrics, 138, 181-207. https://doi.org/10.1016/j.jeconom.2006.05.019

[29] Karolyi, G.A., Lee, K.-H. and van Dijk, M.A. (2012) Understanding Commonality in Liquidity around the World. Journal of Financial Economics, 105, 82-112. https://doi.org/10.1016/j.jfineco.2011.12.008

[30] Chulia, H., Martens, M. and van Dijk, D. (2010) Asymmetric Effects of Federal Funds Target Rate Changes on S\&P 100 Stock Returns, Volatilities and Correlations. Journal of Banking \& Finance, 34, 834-839. https://doi.org/10.1016/j.jbankfin.2009.09.012

[31] Gospodinov, N. and Jamali, I. (2012) The Effects of Federal Funds Rate Surprises on S\&P 500 Volatility and Volatility Risk Premium. Journal of Empirical Finance, 19, 497-510. https://doi.org/10.1016/j.jempfin.2012.04.009

[32] Nikkinen, J. and Sahlstrom, P. (2004) Impact of the Federal Open Market Committee's Meetings and Scheduled Macroeconomic News on Stock Market Uncertainty. International Review of Financial Analysis, 13, 1-12. https://doi.org/10.1016/j.irfa.2004.01.001

[33] Newey, W.K. and West, K.D. (1987) Hypothesis Testing with Efficient Method of Moments Estimation. International Economic Review, 28, 777-787.

https://doi.org/10.2307/2526578 
[34] Amira, K., Taamouti, A. and Tsafack, G. (2011) What Drives International Equity Correlations? Volatility or Market Direction? Journal of International Money and Finance, 30, 1234-1263. https://doi.org/10.1016/j.jimonfin.2011.06.009

[35] Dufour, J.-M., Pelletier, D. and Renault, E. (2006) Short Run and Long Run Causality in Time Series: Inference. Journal of Econometrics, 132, 337-362.

https://doi.org/10.1016/j.jeconom.2005.02.003 